\title{
Size and Shape Effect on Biomedical Applications of Nanomaterials
}

\author{
Balaprasad Ankamwar
}

Additional information is available at the end of the chapter

http://dx.doi.org/10.5772/46121

\section{Introduction}

Fundamental properties of nanomaterials are strong function of their size and shapes. Surfactants are also equally important, since not only it stabilizes the nanoparticles but also makes nanoparticles compatible for various biomedical applications. The different size and shapes of the nanoparticles certainly have an influence and important place in clinical applications.

Earlier, we studied [1] the I-V response of electron transport within the plain and normal to the film surface of gold nanotriangles formed using the crude lemongrass extract. The I-V plot was fairly linear for the out-of-plane measurement while considerably higher across the film surface $(681 \mathrm{k} \Omega)$ than within the plane of the film $(32 \mathrm{k} \Omega)$. This could be due to the field-enhancement effects (FEE) near the sharp vertices of the nanotriangles considerably higher when the electric field was applied parallel to the film surface than when applied normal to the film surface. The FEE near sharp vertices of single crystalline triangular gold nanoprisms (Figure 1A) would be more as compare to truncated (1B) triangular gold nanoprisms. Costa and Dmitriev observed the better field confinement and enhancement in the plane $x y$ for the triangular disk in comparison with the circular disk and circular disk in comparison with the sphere [2]. The FEE could have important application in the use of the sharp vertices biogenic gold nanotriangle as conductive tips in scanning tunneling microscope for studying biological samples. The size of the nanotriangles (thickness: 8-18 $\mathrm{nm}$ ) makes manipulation on to cantilevers feasible for detection of cancer cells by antibodyantigen mechanism.

Ankamwar et al. [3] reported the synthesis of flat and thin sharp vertices single crystalline triangular gold nanoprisms (Figure 1A; thickness: 20-40 nm) using aqueous chloroauric acid solution and tamarind leaf extract and their applications in vapor sensing. Nevertheless, these triangular gold nanoprisms (TGNs) could be used in the biosensing also. 


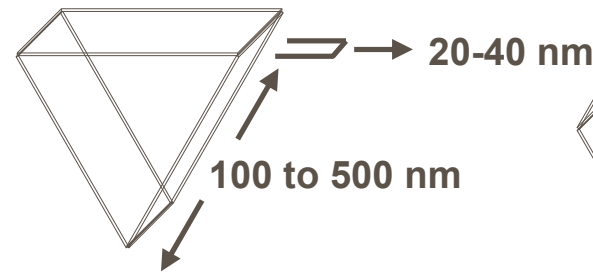

(A)

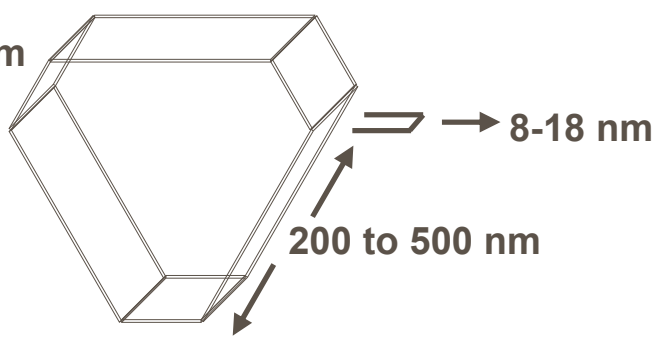

(B)

Figure 1. Schematic diagram of sharp vertices (A) and truncated (B) triangular gold nanoprisms.

Gold nanotriangles have potential applications in hyperthermia of tumors. Triangular gold nanoprisms functionalized by suitable antibody can be delivered by intra-venous injection and preferentially associate with cancerous cells as an effect of strong affection of antibody for corresponding antigens of cancerous cells.

We can selectively kill cancerous cells by focusing IR radiation using laser $(850-1100 \mathrm{~nm})$ to heat up cancerous cells associated with functionalized TGNs, thus hyperthermia of tumors could be exploited for practical purposes. Ankamwar et al. [4] studied the biocompatibility of $\mathrm{Fe}_{3} \mathrm{O}_{4}$ nanoparticles evaluated by in-vitro cytotoxicity assays using normal, glia and breast cancer cells and observed that in all types of cells, nanoparticles were preferentially either adhered to cell membrane or internalized into the cells. The cytotoxic effects seems to be associated principally with an oxidative stress and this stress can result from the generation of reactive oxygen species with the interplay of oxygen with reduced iron species $\left(\mathrm{Fe}^{3+} / \mathrm{Fe}^{2+}\right)$ or from the disturbance of the electronic and/or ionic transport chains due to the strong affinity of the nanoparticles for the cell membrane.

A

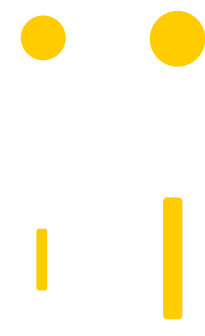

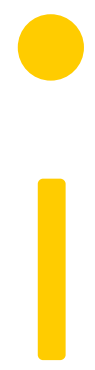

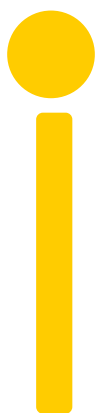

Figure 2. Schematic diagram of spherical (A) and rod (B) shaped gold nanoparticles.

The spherical (Figure 2 A) biogenic gold nanoparticles synthesized using Terminalia catappa leaf extract [5] could be exploited in the use of cancer therapy due to the anticancer [6], antibacterial [7] and antioxidant [8] properties of Terminalia catappa leaf extract. The size of the nanoparticles being in the range 10-35 nm with average size of $21.9 \mathrm{~nm}$ makes their circulation into blood vessels feasible [5]. 
Intrinsic properties such as Surface Plasmon Resonance (SPR) of $\mathrm{Ag}$, $\mathrm{Au}$ metallic nanoparticles (NPs) can be exploited for biosensing, drug delivery, bioimaging; fluorescence and luminescence of semiconductor CdS, CdSe NPs for immunoassays, bioimaging, biosensing; magnetism of magnetic $\mathrm{Fe}_{3} \mathrm{O}_{4}$ for MRI, drug delivery; electronic, mechanical and conductivity of carbon nanotubes (CNTs), and fullerene for drug, gene delivery, therapy and biosensing [9].

Gold nanoparticles, including rods (Figure 2B), enter cells by a non-specific process of endocytosis and concentrate in endosomes [10]. Chithrani et al. [11] studied the effects of size, shape, concentration, and incubation time on kinetics of uptake of nanorods and nanospheres of different sizes into mammalian (HeLa) cells and observed that, the fastest uptake in the case of spheres was for comparatively large particles of $50 \mathrm{~nm}$ diameter. Actually, a similar conclusion was drawn by Osaki et al. [12] for semiconductor nanoparticles, where once again it was the larger particles that more readily entered cells by receptor-mediated endocytosis. Intracellular uptake of gold nanoparticles into cells has been confirmed by imaging in a TEM. This showed that gold nanoparticles in the range of 14 to $100 \mathrm{~nm}$ were located inside cells and trapped in vesicles inside the cytoplasm, and external to the nucleus. Furthermore, the balance of evidence so far is that there is no cytotoxicity associated with the presence of the gold nanoparticles [10]. The change in the shape of the gold nanoparticles from spherical to rod-shaped enables the optical tuning of the SPR to Near Infrared (NIR) biological window region in which biological tissue has high transmitivity. This enables the gold nanorods for in-vivo imaging and therapy, making them highly promising for clinical applications [13]. However, mere spherical and anisotropic structured gold nanoparticles won't be able to solve the problem of target drug delivery. Nevertheless, different combinations of size and shapes with surface properties of nanomaterials need to be considered and implemented. One of the options could be iron oxide@Au spherical Figure 3A and rod Figure 3B shaped core-shell nanoparticles. Researchers are making efforts to find best possible option for cancer treatment using various combinations of nanoparticles by exploiting size and shapes effect of nanomaterials on their properties. As a result promising results are obtained. Hence, a revolution in nanotechnology is growing interest, however it is important to understand the how nanomaterials interact with biological systems especially for biomedical applications. Brief outline of biomedical applications of various nanomaterials with their different size and shapes is presented in this article.

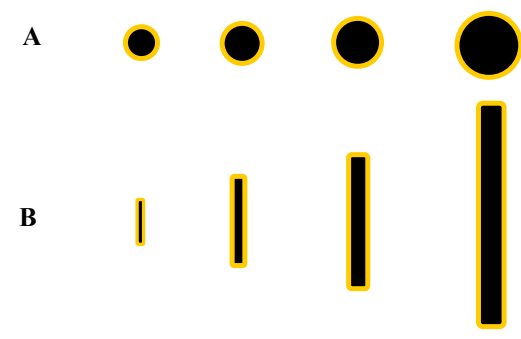

Figure 3. Schematic diagram of spherical (A) and rod (B) shaped iron@Au core-shell nanoparticles. 


\section{Application area}

\subsection{Role of size and shape of nanomaterials in biomedical applications}

The role of proper size and shape of nanomaterials is un-debatable in biomedical applications. Moreover, multifaceted aspects of size and shapes of nanomaterials always remain inspiration to many researchers in this domain. Nevertheless, classification of particles is inevitable in this context.

Particles can be classified according their size, in terms of diameter; coarse particles in a range between 10,000 and 2,500 $\mathrm{nm}$, fine particles, 2,500 and $100 \mathrm{~nm}$ and ultrafine particles or nanoparticles 100 and $1 \mathrm{~nm}$ [14].

\subsection{Nanoparticles selection based on size, shape and surface}

Selection of nanoparticles is indispensable step prior its application and it should be based on their earlier reported effects and potential effects with consideration of size, shape and surface.

\subsubsection{Size}

Size determines the surface to volume ratio, and can strongly affect the material uptake and biodistribution, e.g. drug loaded nanoparticles can be used for site specific drug delivery only when uptake and blood circulation could be feasible. Blood Brain Barrier (BBB) and Blood Retina Barrier (BRB) like problems are still challenging task for site specific drug delivery due to size problem.

\subsubsection{Shape}

Shape is critical parameter which effects cell uptake and/or the rate and site specific drug delivery from the system. Preferential interaction with specific proteins could be achieved on proper shape selection of nanomaterials.

\subsubsection{Surface}

Surface and/or functionalized surface of nanomaterial has a special significance, since surface molecules determine the particles hydrophobic or hydrophillic, lipophobic or lipophillic, nature of particles and the extent to which they will interact with other molecules or trigger an immune response [15].

Non linear optical properties of nanostructured materials [16-18] can be useful in optoelectronics. Size and shape dependent properties of noble nanomaterials are resulting in the strong scattering and absorption of light [19-21] due to large optical field enhancement, however in semiconductors, due to the confinement of the electronic motion to a length scale that is comparable to or smaller than the length scale characterizing the electronic 
motion in bulk semiconducting material [22-24]. In case of noble metals, as the size is reduced to tens of nanometers scale, a new very strong absorption is observed, due to the collective oscillation of the electrons in the conduction band from one surface of the particle to the other. $[25,26]$.

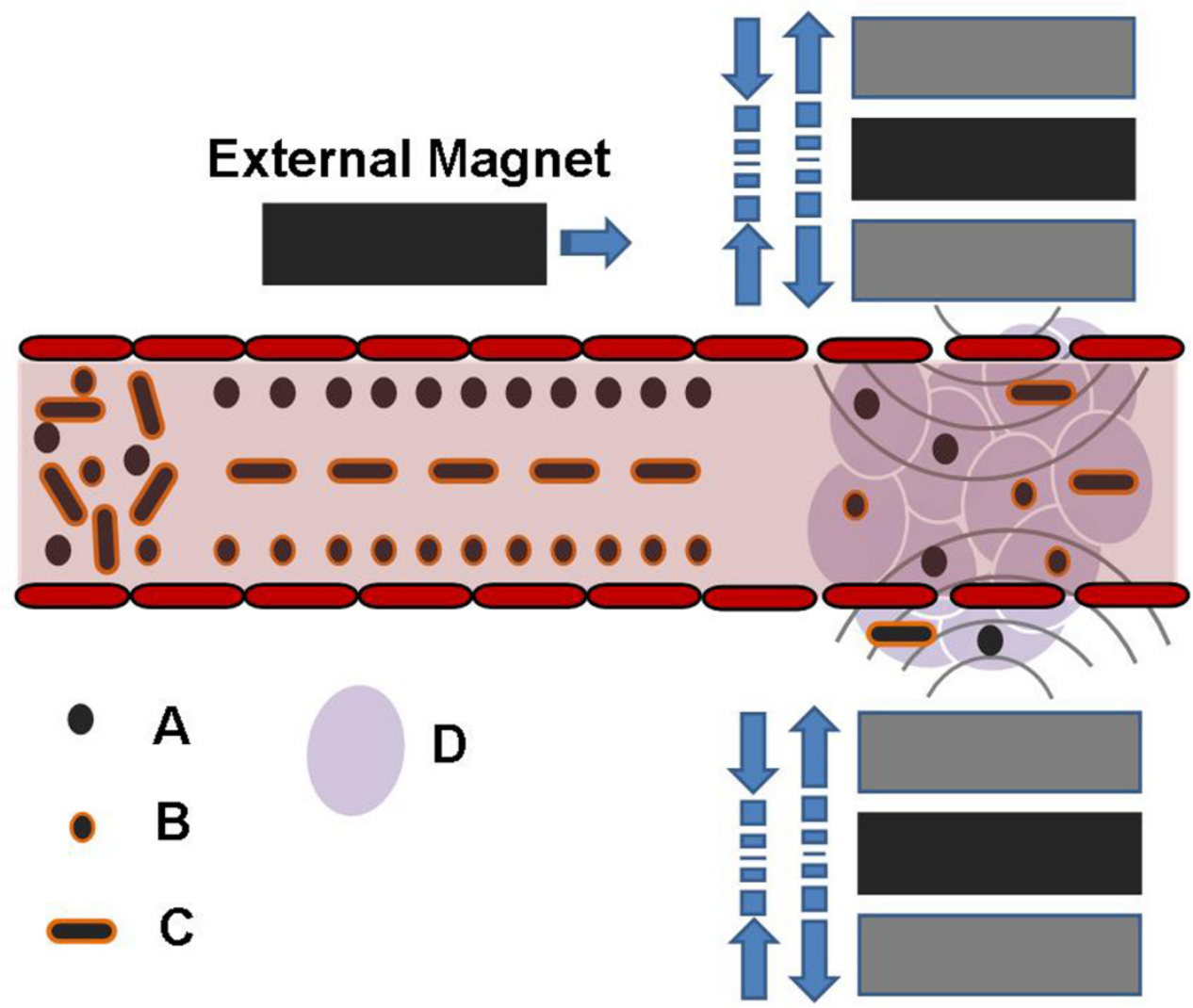

Figure 4. Schematic diagram of cell target delivery and hyperthermia of tumors under the influence of alternating magnetic field: iron nanospheres (A), iron@Au core-shell nanosphere (B), iron@Au core-shell nanorods (C) and cancer cells (D).

\subsection{Targeted drug delivery by nanoparticles}

Targeted drug delivery, is to confine, target and have a protected drug interaction with the diseased tissue. The advantages of the targeted release system are the less number of dosages to the patient, whereas the disadvantage of the high cost may not be affordable by the patient. Cost reduction without affecting drug efficiency against the diseased tissue is prime demand of the society. Due to high surface to volume ratio and less cost as compare to bulk materials, nanoparticles could be the best option in this regard. 


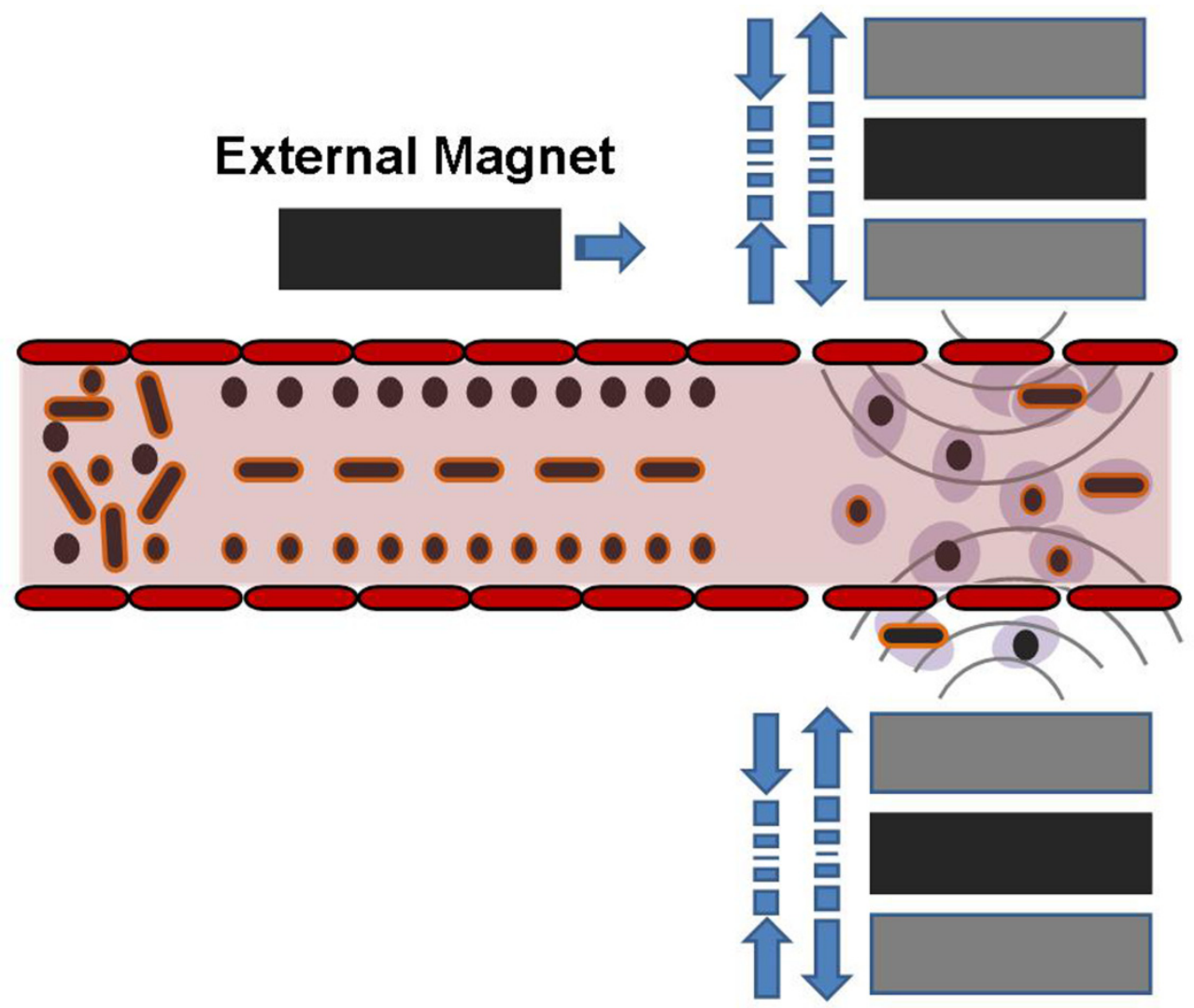

Figure 5. Schematic diagram depicting cell contraction under the influence of alternating magnetic field.

\section{External Magnet}

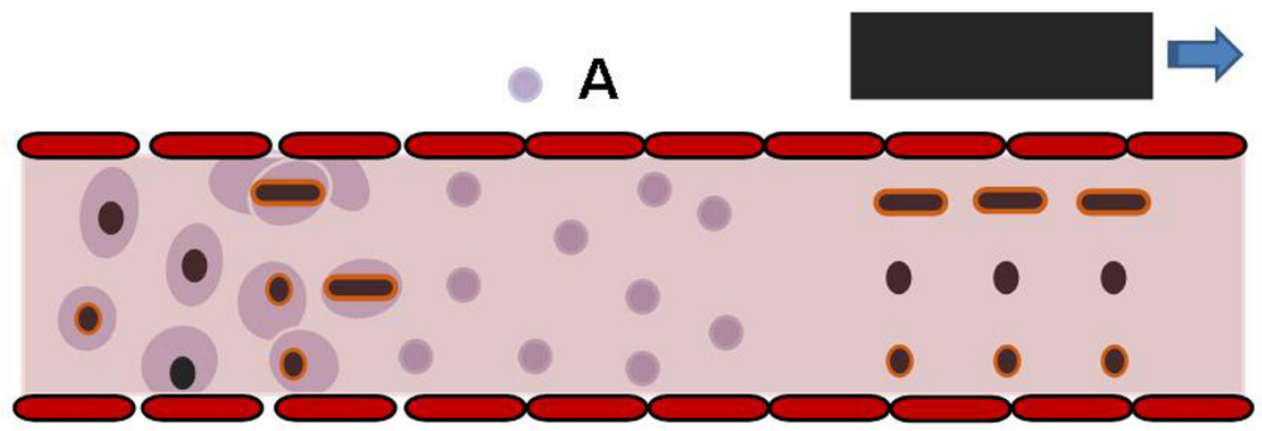

Figure 6. Schematic diagram depicting cell death (A) and excretory organ delivery of nanoparticles under the influence of external magnetic field. 


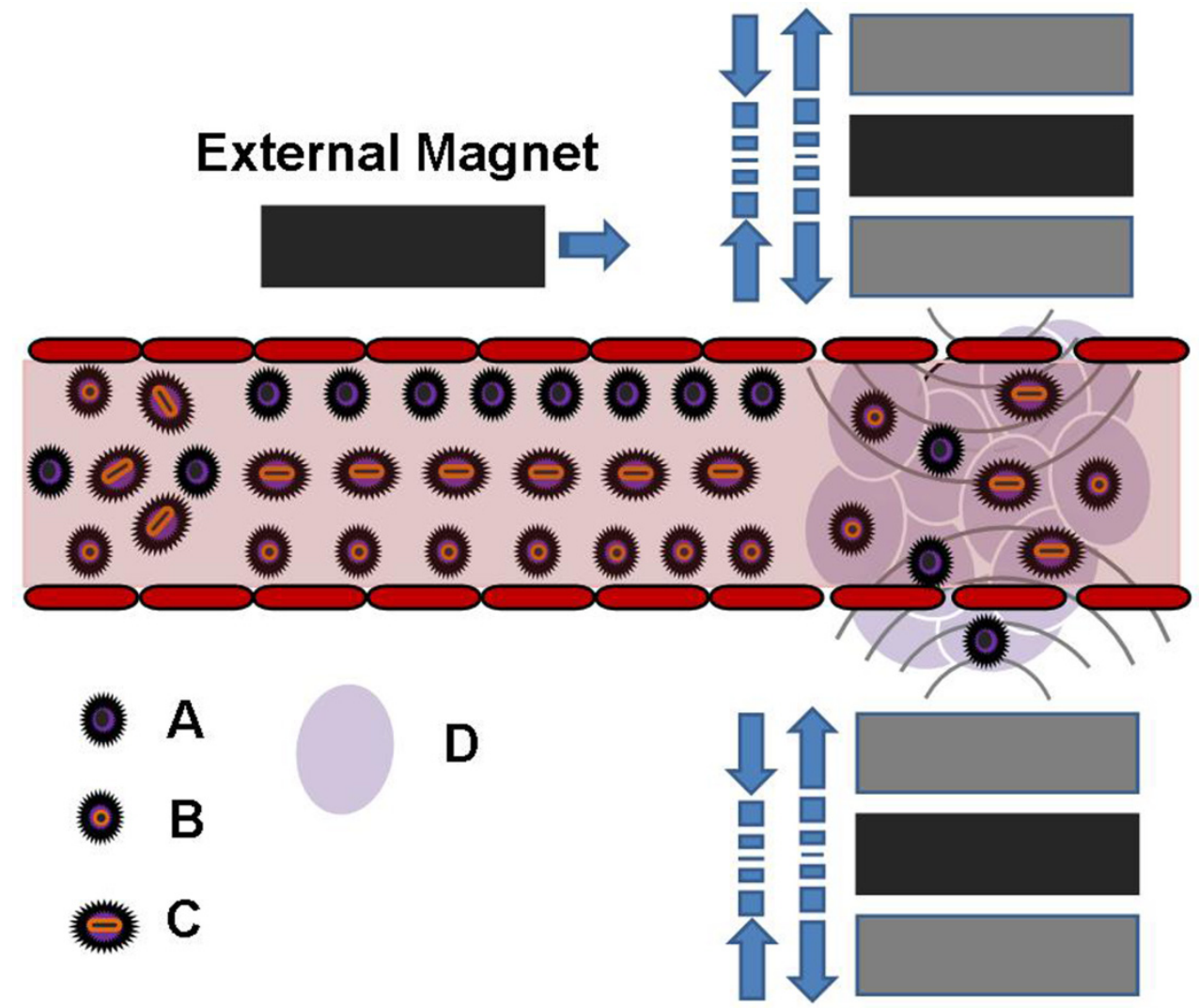

Figure 7. Schematic diagram of cell target drug delivery and hyperthermia of tumors under the influence of alternating magnetic field: iron@drug (A), iron@Au@drug core-shell nanosphere (B), iron@Au@drug core-shell nanorods (C) and cancer cells (D).

Figure 4-9: shows intravenous injection of nanoparticles

\subsection{The role of blood vessel}

The blood vessels are the part of the circulatory system that transports blood throughout the body. Hence, it is frequently adopted for delivery of the drug for a sustained period of time to target diseased area. Frankly speaking, the drug delivery system requires various disciplines, such as chemists, biologist and engineers, to join forces to optimize this system.[27]. In case of anticancer drug to effective in cancer treatment they should be able to reach the desired tumor with minimal loss of their volume and activity in the blood circulation. Moreover, after reaching the tumor tissue, they should have selectivity in killing tumor cells without affecting normal cells. Here, the number of doses can be reduced with extra benefit of fewer side effects of extra doses of drug in existing methodology. Nanoparticles of appropriate size and shape can be used as effective drug carrier. 


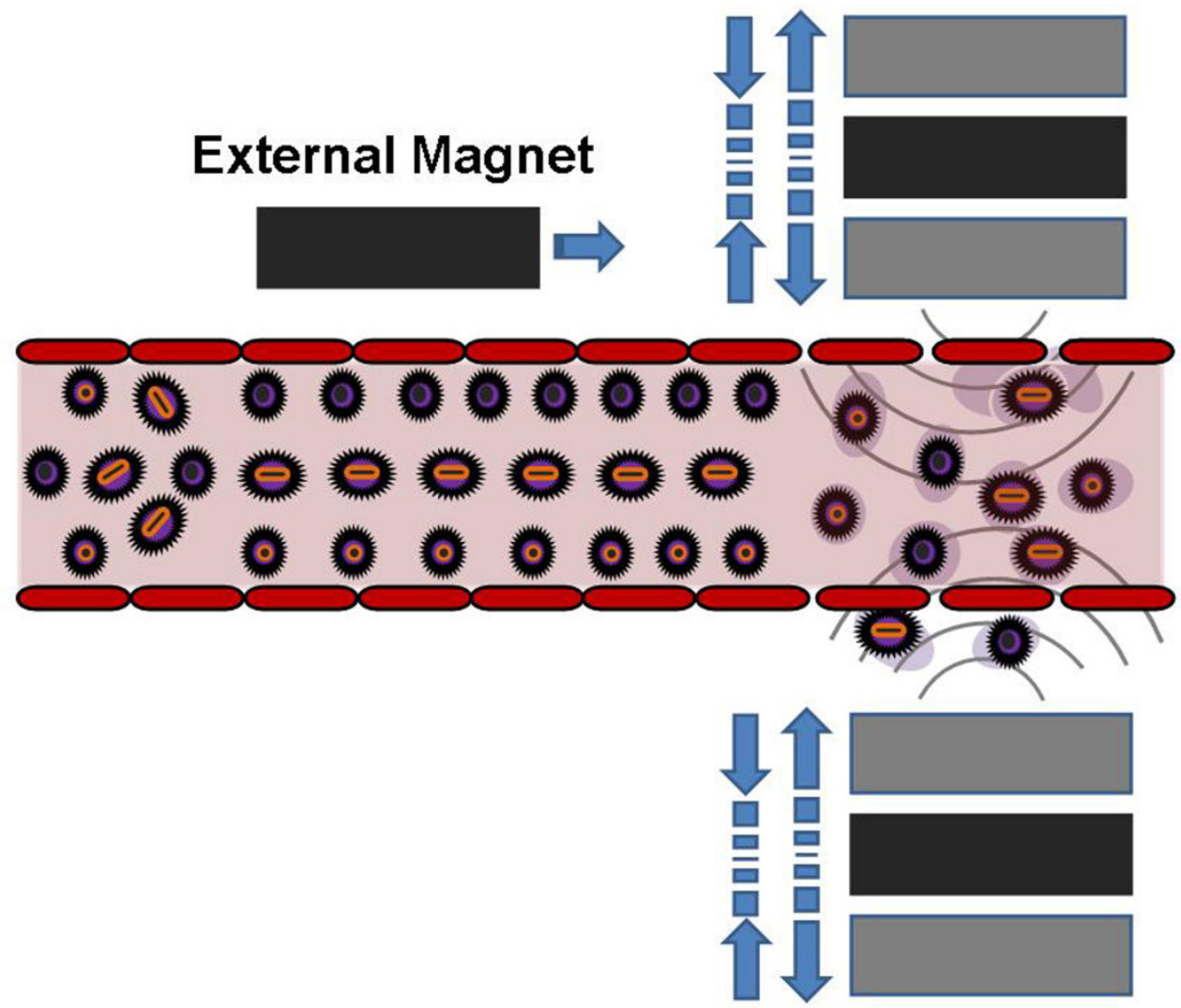

Figure 8. Schematic diagram depicting cell contraction under the combine effect of drug and hyperthermia of tumors due to the alternating magnetic field.

\section{External Magnet}

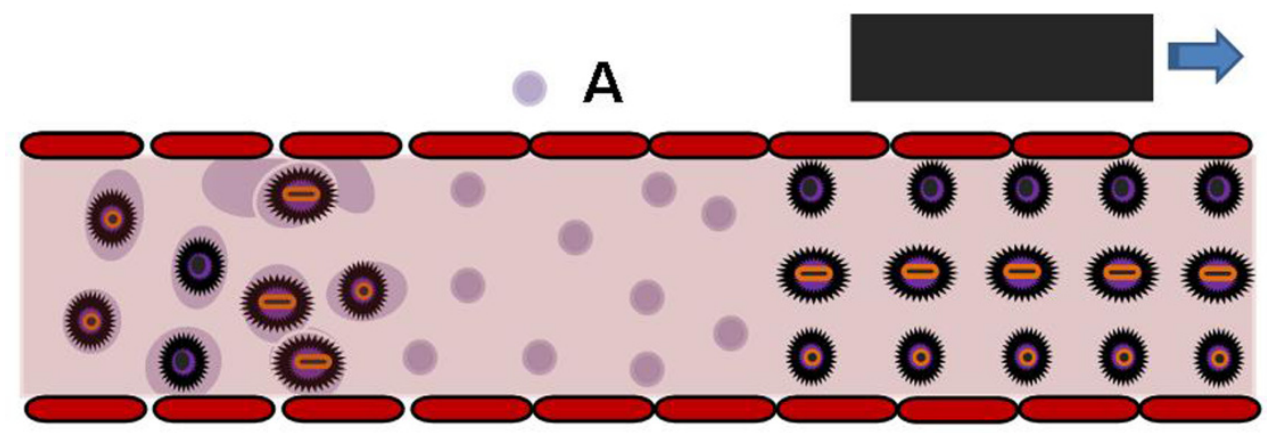

Figure 9. Schematic diagram depicting cell death (A) and excretory organ delivery of nanoparticles under the influence of external magnetic field. 


\subsection{The significance of size, shape and surface characteristics of nanoparticles in biomedical applications}

Drug loaded nanoparticles should remain sufficient period in blood stream to interact with an active site of the drug with the tumor. Conventional surface non reformed nanoparticles are usually trapped in the circulation by the reticulo endothelial system, such as the liver and the spleen, reliant on their size and surface characteristics [28]. Hence, size, shape and surface characteristics play significant role in tumor targeted drug delivery.

Lia [29] presented a thermodynamic approach to elucidate the effects of the size and shape of nanoparticles on endocytosis. It was found that endocytosis needs to surmount a thermodynamic energy barrier and has a minimum radius of nanoparticles for endocytosis. Through referring to the concept of "diffusion length of receptors," he obtained a simple and analytical expression for the optimal size of nanoparticles and suggested that the spherical nanoparticles with the optimal radius about $25 \mathrm{~nm}$ have the fastest endocytosis speed. Pan et al. [30] reported that the cytotoxicity of $\mathrm{Ph}_{2} \mathrm{PC}_{6} \mathrm{H}_{4} \mathrm{SO}_{3} \mathrm{Na}$ (TPPMS) and trissulfonated triphenylphosphine $\mathrm{P}_{(}\left(\mathrm{C}_{6} \mathrm{H}_{4} \mathrm{SO}_{3} \mathrm{Na}\right)_{3}$ TPPTS-modified gold nanoparticles depended primarily on their size and not on ligand chemistry. Particles of 1-2 nm in size were highly toxic and both smaller gold compounds (Tauredon) and larger 15-nm gold colloids were comparatively nontoxic.

\subsubsection{Significance of size}

Small size of nanoparticles are preferred, since after drug loading overall diameter should be more than enough to circulate though out the blood circulatory network for sustained period of time. Ankamwar et al. [4] reported synthesis of $\sim 5 \mathrm{~nm} \mathrm{Fe}_{3} \mathrm{O}_{4}$ nanoparticles using modified earlier reported protocol [31] and studied their biocompatibility with breast and brain cancer cells. These nanoparticles could be the one of the best option to use it as drug carrier. The size of the sinusoid in the spleen and fenestra of the Kuffer cells in the liver varies from 150 to $200 \mathrm{~nm}$ [32] and the size of gap confluence between endothelial cells of the leaky tumor vasculature may vary from 100 to $600 \mathrm{~nm}$ [33]. This suggests that, the size of nanoparticles should not be above $100 \mathrm{~nm}$ to reach tumor tissues by passing through these two particular vascular structures. However, Elsabahy and Wooley [34] suggested that intermediate sizes $(20-200 \mathrm{~nm})$ have the highest potential for in-vivo applications.

\subsubsection{Significance of shape}

Shape of nanoparticles is also equally important in sustained drug delivery as good as their size. Spherical nanoparticles are good option for drug delivery; however anisotropic structures could be the best option due to their large surface area e.g. dendrimer. This kind of structures can make good seating and binding arrangements for the drug which can be useful for sustained drug delivery. However, sharp edges of anisotropic structures can be responsible for injury of blood vessels [35]. 
The mechanism that allows nanoparticles to cross the cell membrane has been the subject of much recent research because the understanding and control of such uptake processes is important for the development of nanomedicine [35, 36]. Cellular uptake through endocytosis is crucial for drug delivery and nanomedicine. However, the conditions under which passive endocytosis (i.e. not ATP driven) takes place are not well understood. We report MD simulations of the passive uptake of ligand-coated nanoparticles with varying size, shape, coverage, and membrane-binding strength. They found that the efficiency of passive endocytosis was higher for spherocylindrical particles than for spheres and that endocytosis was suppressed for particles with sharp edges.

\subsubsection{Significance of surface characteristics of nanoparticles}

In addition to their size and shape, the surface characteristics of nanoparticles are also an indispensable factor determining their life span, fate during circulation, drug binding and site specific release. Nanoparticles should ideally have a hydrophilic surface to escape macrophage capture [37]. This can be achieved in two ways: coating the surface of nanoparticles with a hydrophilic polymer, such as PEG, protects them from plasma proteins; alternatively, nanoparticles can be formed from block copolymers with hydrophilic and hydrophobic domains [38, 39].

However, Elsabahy and Wooley [34] suggested that the surface chemistry of the nanomaterials greatly impact their toxicity, immunogenicity, biodistribution and excess positive charge results in rapid opsonization and clearance with possible blood vessels and capillary occlusion.

\subsubsection{Significance of nanoshells}

When the nanoshells are used for the drug delivery these shells wrap the tumor cells. When external field of infrared light is applied the tumor cells gets destroyed and the normal cells are left unaffected. Nanoshells tuned to absorb NIR radiation are particularly useful as mediators of photo thermal cancer therapy because they efficiently convert absorbed radiation into heat, and are thermally stable at therapeutic temperatures. The inert gold surface of nanoshells provides several advantages, including biocompatibility, non cytotoxicity, and it also facilitates conjugation to monoclonal antibodies or other biomolecules for both active tumor targeting and biosensing applications.

Nanoshells exhibit unique properties because their interaction with the electromagnetic field is greatly intensified by a phenomenon known as Localized Surface Plasmon Resonance (LSPR). This resonance effect arises from the collective oscillation of the conduction electrons in the gold shell, which efficiently couple to the incident electromagnetic field, and propagate along the surface [40].

\subsection{Comparison between nanorods and nanospheres}

The use of spherical gold nanoparticles are common practice for drug delivery, however the use of gold nanorods, have the promising feature in this regard. The nanorods of different 
lengths absorb different frequencies of infrared radiation. It is shown that gold nanorods absorb infrared much more efficiently than spherical gold nanoparticles. Therefore gold nanorods do a better job of absorbing infrared light and heating up the tumor than spherical nanoparticles do [41]. Hence, could be the best option in hyperthermia of tumors. Mere absorption of infrared light to maximum extent does not solve destruction of tumor problem. Magnetic nanoparticles such as spherical and rod shaped $\mathrm{Fe}_{3} \mathrm{O}_{4}$ coated with gold could be the better option, since magnetic $\mathrm{Fe}_{3} \mathrm{O}_{4}$ nanoparticles can be utilized for site specific drug delivery under the influence of applied external magnetic field and gold coating for hyperthermic destruction of tumors. Obviously, triangular gold nanoprisms would be the best option than rod shaped nanoparticles and rod shaped nanoparticles would be better option than spherical nanoparticles.

\subsection{Thermotherapy or hyperthermia of tumors}

Hyperthermia is one of the many treatment options that may be used in treating cancer. Hyperthermia therapy is a type of medical treatment in which body tissue is exposed to slightly higher temperatures to damage and kill cancer cells or to make cancer cells more sensitive to the effects of radiation and certain anti-cancer drugs [42, 43]. When combined with radiation therapy, it is called thermoradiotherapy. The preferential killing of cancer cells without damaging normal cells has been a desired goal in cancer therapy for many years. However, the various procedures used to date, including chemotherapy, radiotherapy or surgery, can fall short of this aim [44]. The potential of hyperthermia as a treatment for cancer was first predicted following observations that several types of cancer cells were more sensitive to temperatures in excess of $41^{\circ} \mathrm{C}$ than their normal counterparts [45, 46]. In the past external means of heat delivery were used such as ultrasonic or microwave treatments, but more recently research has focused on the injection of magnetic fluids directly into the tumour body, or into an artery supplying the tumour. The magnetic fluids used are preferably suspensions of super paramagnetic particles, prepared much as described for MRI contrast agents, as these produce more heat per unit mass than larger particles [47]. The level heating is simply controlled by the materials Marie Curie temperature, that is, the temperature above which materials loses their magnetic properties and thus their ability to heat [48]. There are two approaches, the first is called magnetic hyperthermia and involves the generation of temperatures up to $45-47^{\circ} \mathrm{C}$ by the particles. This treatment is currently adopted in conjunction with chemotherapy or radiotherapy, as it also renders the cells more sensitive [49]. The second technique is called magnetic thermoblation, and uses temperatures of $43-55^{\circ} \mathrm{C}$ that have strong cytotoxic effects on both tumour and normal cells $[45,50]$. The reason for this use of increased temperatures is due to the fact that about $50 \%$ of tumours regress temporarily after hyperthermic treatment with temperatures of up to $44^{\circ} \mathrm{C}$, therefore authors prefer to use temperatures up to $55^{\circ} \mathrm{C}$ [50]. On the basis of recent studies, tumours with volumes of approximately $300 \mathrm{~mm}^{3}$ can be heated and no potential problems were expected with larger tissue volumes (e.g. $>1000 \mathrm{~mm}^{3}$ ) if there is proper regulation of the magnetic mass used and the intra-tumoural particle distribution [50]. The frequency should 
be greater than that sufficient to cause any neuromuscular response, and less than that capable of causing any detrimental heating of healthy tissue, ideally in the range of 100-1000 $\mathrm{kHz}[51,52])$. If suitable frequencies and field strength combinations are used, no interaction is observed between the human body and the field.

Various different types of nanocrystallites such as iron nanospheres Figure 4 (A), iron@Au core-shell nanosphere (B), iron@Au core-shell nanorods (C) may be injected intravenously. These nanoparticles are randomly oriented at the point of injection; however under the influence of magnetic field, they can be oriented in proper direction. External magnet can be used for proper orientation and site target delivery of magnetic nanoparticles as shown in Figure 4 alternating magnets generate heat to kill cancer cells. The method relies on the theory that any metallic objects when placed in an alternating magnetic field will have induced currents flowing within them. The amount of current is proportional to the size of the magnetic field and the size of the object [44]. As these currents flow within the metal, the metal resists the flow of current and thereby heats, a process termed inductive heating. If the metal is magnetic, such as iron, the phenomenon is greatly enhanced. Therefore, when a magnetic fluid is exposed to an alternating magnetic field the particles become powerful heat sources, destroying the tumour cells [51, 52] (Figure 5). The proper disposal of dead tumor cells and magnetic particles is also equally important. External magnetic field can be utilized to direct magnetic particles towards excretory organ as shown in Figure 6. Superparamagnetic iron oxide nanoparticles have been used for many years as Magnetic Resonance Imaging (MRI) contrast agents [53], receptor-mediated targeting of magnetic nanoparticles using insulin as a surface ligand to prevent endocytosis. However, gold coated spherical or rod iron nanoparticles can be better option for their scattering properties for imaging and laser therapy both combine together along with magnetic properties of iron nanoparticles. Gold coated iron nanorods could be the best option for thermotherapy in addition to imaging and laser therapy, since gold nanorods absorb infrared radiation better than spherical gold particles.

Tissue and cell-specific drug targeting by superparamagnetic iron oxide nanoparticles can be achieved by employing nanoparticles coatings or carrier-drug conjugates that contain a ligand recognized by a receptor on the target cell. In this study, superparamagnetic iron oxide nanoparticles with specific shape and size have been prepared and coupled to insulin for their targeting to cell expressed surface receptors and thereby preventing the endocytosis [53]. Figure 7 depicts a schematic diagram of cell target drug delivery and hyperthermia of tumors under the influence of alternating magnetic field: iron@drug (A), iron@Au@drug coreshell nanosphere (B), iron@Au@drug core-shell nanorods (C) and cancer cells (D). Figure 8 shows tumor cell death and Figure 9 the proper disposal of dead tumor cells and magnetic particles towards excretory organs. Here magnetic particles are intended to use for tumor specific site delivery under the influence of external magnetic field and hyperthermia of tumors. However, gold coating can be used to loading drug and imaging due to scattering properties of gold nanoshell. Obviously, gold coated nanorods would be best option due to infrared absorption properties of gold nanorods, which in turn can be used for laser therapy. 
The best combination of various therapies such as chemotherapy by tumor specific drug delivery, thermotherapy (hyperthermia) and laser therapy would be the most suitable option to solve cancer problem to maximum extent as depicted in Figure 7-9. Many oncologists agree with multi therapy rather than any single therapy for cancer treatment. Since in many type of cancer cells single therapy did not show $100 \%$ cure.

\subsection{Advantages of nanorods over nanospheres}

By combining the delivery of rods with drugs, tumor death is triggered with minimizing toxicity by a combination of chemotherapy and external laser beam stimulation. Apart from an initial laser cost, the combination of these two drugs would be relatively noninvasive and inexpensive [54].

We also note that silica nanospheres with a nanoscale overcoat of gold ("nanoshells") also have tunable absorption in the visible and NIR, and these materials are the subject of another recent review [55].

\begin{tabular}{|c|c|c|c|c|c|}
\hline Author & $\begin{array}{l}\text { Size } \\
(\mathrm{nm})\end{array}$ & Shape & Surface group & Cell line & Toxicity results \\
\hline \begin{tabular}{|l} 
Ankamwar \\
et al. $[4]$
\end{tabular} & $\sim 5 \mathrm{~nm}$ & Sphere & $\mathrm{COOH}, \mathrm{NH}_{2}$ & $\begin{array}{l}\text { U-251 Glia cancer } \\
\text { cells }\end{array}$ & $\begin{array}{l}75.4 \pm 7.2 \text { cell viability after } \\
\text { being exposed to } 100 \mu \mathrm{MFe}_{3} \mathrm{O}_{4} \\
\text { nanoparticles for } 72 \mathrm{~h} \text {. }\end{array}$ \\
\hline $\begin{array}{l}\text { Ankamwar } \\
\text { et al. [4] }\end{array}$ & $\sim 5 \mathrm{~nm}$ & Sphere & $\mathrm{COOH}, \mathrm{NH}_{2}$ & $\begin{array}{l}\text { T47D Breast cancer } \\
\text { cells }\end{array}$ & $\begin{array}{l}81.8 \pm 7.6 \text { cell viability after } \\
\text { being exposed to } 100 \mu \mathrm{MFe}_{3} \mathrm{O}_{4} \\
\text { nanoparticles for } 72 \mathrm{~h} \text {. }\end{array}$ \\
\hline \begin{tabular}{|l} 
Jie Pan \\
et al. $[56]$
\end{tabular} & $\begin{array}{l}280- \\
300 \\
\mathrm{~nm}\end{array}$ & Sphere & $\begin{array}{l}\text { TPGS-COOH, } \\
\text { PEG }\end{array}$ & $\begin{array}{l}\text { MCF-7 } \\
\text { breast cancer cells } \\
\text { and NIH 3T3 cells }\end{array}$ & $\begin{array}{l}\text { In vitro cell viability of MCF-7 } \\
\text { cells treated with free QDs is } \\
80 \% \text {, QDs-loaded } 11.1 \% \text { (tri- } \\
\text { noctylphosphine oxide (TOPO)- } \\
\text { capped QDs) TC NPs is } 95 \% \\
\text { and QDs-loaded } 11.1 \% \text { (folate- } \\
\text { decorated) FD NPs is } 82 \% \text { at the } \\
\text { same } 0.63 \text { nMQDs } \\
\text { concentration after } 4 \mathrm{~h} \text { and } 24 \mathrm{~h} \text {. } \\
\text { In vitro cell viability of NIH } \\
3 \mathrm{~T} 3 \text { cells treated with free QDs } \\
\text { is } 87 \% \text {, QDs-loaded } 11.1 \% \text { TC } \\
\text { NPs is } 90 \% \text { and QDs-loaded } \\
11.1 \% \text { FD NPs } 89 \% \text { at the same } \\
0.63 \mathrm{nMQDs} \text { concentration } \\
\text { after } 4 \mathrm{~h} \text { and } 24 \mathrm{~h} \text {. }\end{array}$ \\
\hline \begin{tabular}{|l|} 
Niidome \\
et al. [57]
\end{tabular} & $65 \mathrm{~nm}$ & Rod & CTAB, PEG & HeLa cells & $\begin{array}{l}80 \% \text { cell death with } 0.05 \\
\text { mMCTAB-coated nanorods, } \\
\text { only } 10 \% \text { of cell death at } 0.5 \\
\text { mM PEG coated nanorods. }\end{array}$ \\
\hline $\begin{array}{l}\text { Takahashi } \\
\text { et al. [58] }\end{array}$ & $65 \mathrm{~nm}$ & Rod & $\begin{array}{l}\text { Phospatidyl } \\
\text { choline }\end{array}$ & HeLa cells & $\begin{array}{l}\text { Phosphatidylcholine modified } \\
\text { gold nanorods were much less }\end{array}$ \\
\hline
\end{tabular}




\begin{tabular}{|c|c|c|c|c|c|}
\hline Author & $\begin{array}{l}\text { Size } \\
(\mathrm{nm})\end{array}$ & Shape & Surface group & Cell line & Toxicity results \\
\hline & & & & & $\begin{array}{l}\text { toxic than C-TAB coated } \\
\text { nanorods. }\end{array}$ \\
\hline \begin{tabular}{|l|} 
Sun \\
et al. [59]
\end{tabular} & --- & --- & --- & \begin{tabular}{|l|} 
Sarcoma 180 mouse \\
tumor cell line (S180) \\
and SGC-7901 \\
human \\
gastric carcinoma \\
cell line \\
(SGC-7901)
\end{tabular} & $\begin{array}{l}\text { The concentration of the gold } \\
\text { complexes is } 32 \mu \mathrm{M} \text {. } \\
\text { Sarcoma } 180 \text { mouse tumor cell } \\
\text { line S180cell human gastric } \\
\text { carcinoma cell line SGC- } \\
7901 \text { cell. } \\
\text { ClAuTCPPNa treated with } \\
\text { S180 cell and SGC-7901 cell } \\
\text { shows cell viability } 66.63 \% \text { and } \\
57.93 \% \text { respectively. } \\
\text { ClAuTPPCOONa treated with } \\
\text { S180 cell and SGC-7901 cell } \\
\text { shows cell viability } 16.46 \% \text { and } \\
50.47 \% \text { respectively. } \\
\text { The result showed that the } \\
\text { anti-tumor activity of } \\
\text { ligandTCPPNa is lower than } \\
\text { its gold(III) complex. }\end{array}$ \\
\hline $\begin{array}{l}\text { Temminka } \\
\text { et al. }[60]\end{array}$ & --- & -- & --- & WiDr and H630 & $\begin{array}{l}\text { The cell viability of WiDr cells } \\
\text { treated with TFTc at } 2 \mathrm{nM} \\
\text { shows } 95 \% \text { after } 72 \mathrm{hrs} \text {. } \\
\text { The cell viability of } \mathrm{H} 630 \text { cells } \\
\text { treated with TFTc at } 0.5 \mathrm{nM} \\
\text { shows } 95 \% \text { after } 72 \text { hrs. }\end{array}$ \\
\hline \begin{tabular}{|l|} 
Wei \\
et al. [61]
\end{tabular} & $\begin{array}{l}10-30 \\
\mathrm{~nm}\end{array}$ & Sphere & $\begin{array}{l}\text { MAA-coated } \\
\text { nanoparticles }\end{array}$ & $\begin{array}{l}\text { CBRH7919 liver } \\
\text { cancer } \\
\text { cells }\end{array}$ & $\begin{array}{l}\text { CdS-based QDs was prepared } \\
\text { and cellular imaging was } \\
\text { conducted. The (QDs) CdS- } \\
\text { MAA-PEI-FA has highly } \\
\text { photostable and very excellent } \\
\text { water-dispersibility and } \\
\text { bioimaging. By use of confocal } \\
\text { microscopy, demonstrated the } \\
\text { internalization of QD-MAA- } \\
\text { PEI-FA in FRs (folate } \\
\text { receptors) over expressing } \\
\text { tumor cells such as } \\
\text { CBRH7919livercancer cell and } \\
\text { their receptor-mediated uptake } \\
\text { is confirmed by the rapid } \\
\text { uptake (in less than } 3 \mathrm{~h} \text { ). }\end{array}$ \\
\hline \begin{tabular}{|l|} 
Abbasalipou \\
rkabir \\
et al. $[62]$
\end{tabular} & $\begin{array}{l}145.00 \\
\pm 3.39\end{array}$ & Sphere & $\begin{array}{l}30 \% \text { lecithin and } \\
1 \% \text { oleyl alcohol }\end{array}$ & $\begin{array}{l}\text { MCF-7 and MDA- } \\
\text { MB231 }\end{array}$ & $\begin{array}{l}\text { Cell viability of MCF-7 MDA- } \\
\text { MB231 and cells treated with } \\
\text { SLN-03 for } 72 \mathrm{hr} \text { is } 45 \text { and 50\% } \\
\text { respectively. }\end{array}$ \\
\hline $\begin{array}{l}\text { Pourgholami } \\
\text { et al. }[63]\end{array}$ & --- & |--- & $\begin{array}{l}\text { ABZ-CD + citric } \\
\text { acid (CA) }\end{array}$ & $\begin{array}{l}\text { human ovarian } \\
\text { cystadenocarcinoma }\end{array}$ & $\begin{array}{l}\text { The cell viability of human } \\
\text { heptocytes cells treated with }\end{array}$ \\
\hline
\end{tabular}




\begin{tabular}{|c|c|c|c|c|c|}
\hline Author & $\begin{array}{l}\text { Size } \\
(\mathrm{nm})\end{array}$ & Shape & Surface group & Cell line & Toxicity results \\
\hline & & & & $\begin{array}{l}\text { cancer cell lines 1A9, } \\
\text { OVCAR-3 and } \\
\text { SKOV-3 }\end{array}$ & $\begin{array}{l}\text { ABZCD+CA(albendazole } \\
\beta \text {-cyclodextrins + citric acid) at } \\
1 \mu \mathrm{M} \text { shows } 90 \% \text { after } 3 \text { days. }\end{array}$ \\
\hline \begin{tabular}{|l} 
Yong \\
et al. [64]
\end{tabular} & --- & Rods & CTAB & $\begin{array}{l}\text { Pancreatic cancer } \\
\text { cell } \\
\text { lines }\end{array}$ & $\begin{array}{l}\text { The cell viability of Panc- } 1 \\
\text { treated with anti-claudin } 4 \text { and } \\
\text { drug conjugated QDs with } \\
\text { ADM at } 1.1 \mu \mathrm{M} \text { shows } 66 \% \text { for } \\
24 \mathrm{~h} \text {. }\end{array}$ \\
\hline \begin{tabular}{|l|} 
Glazer \\
et al. [65]
\end{tabular} & ------ & Sphere & PEG & $\begin{array}{l}\text { Panc-1 or Cama-1 } \\
\text { cells }\end{array}$ & $\begin{array}{l}\text { Cell viability greater than } 92 \% \\
\text { CdSe quantum dot toxicity has } \\
\text { been reported at } \\
\text { concentrations greater than } 0.8 \\
\mu \mathrm{M} .26 \text { indium based quantum } \\
\text { dots InGaPhosphide (i.e., } \\
\text { eFluorNC700) are ten times } \\
\text { less toxic. }\end{array}$ \\
\hline \begin{tabular}{|l|} 
Das \\
et al. [66]
\end{tabular} & $8 \mathrm{~nm}$ & Sphere & \begin{tabular}{|l|} 
poloxamers,polo \\
xamines or \\
polyethylene \\
glycol (PEG) \\
derivatives
\end{tabular} & $\begin{array}{l}\text { human cervical } \\
\text { HeLa cancer cells, }\end{array}$ & $\begin{array}{l}\text { The cell viability of HeLa cells } \\
\text { treated with folate conjugated } \\
\text { magnetite NPs at } 200 \mu \mathrm{g} / \mathrm{ml} \text { of } \\
\text { magnetite NPs is } 97 \% \text {. } \\
\text { No significant reduction in } \\
\text { cellular viability was observed, } \\
\text { the survival rate being higher } \\
\text { than } 90 \% \text {, even at the highest } \\
\text { nanoparticle concentration. }\end{array}$ \\
\hline \begin{tabular}{|l|} 
Gupta \\
et al. [53]
\end{tabular} & $\begin{array}{l}550 \\
\mathrm{~nm}\end{array}$ & --- & Insulin & \begin{tabular}{|l} 
Infinity telomerase- \\
immortalized \\
primary human \\
fibroblasts \\
(hTERT-BJ1, \\
Clonetech \\
Laboratories, Inc., \\
Hampshire, U.K.)
\end{tabular} & $\begin{array}{l}\text { Insulin-coated nanoparticles } \\
\text { revealed no cytotoxic effects to } \\
\text { cells, and they remained more } \\
\text { than } 100 \% \text { viable relative to } \\
\text { control at concentration as } \\
\text { high as } 1 \mathrm{mg} / \mathrm{ml} \text {. } \\
\text { Incubation with uncoated } \\
\text { plain magnetic particles, the } \\
\text { fibroblasts showed significant } \\
\text { loss in viability of about } 25 \% \text { - } \\
50 \% \text { observed at } \\
\text { concentrations } 250 \mathrm{~g} / \mathrm{ml} \text {. }\end{array}$ \\
\hline \begin{tabular}{|l} 
Ahrens \\
et al. [67]
\end{tabular} & $\begin{array}{l}\sim 50 \\
\mathrm{~nm}\end{array}$ & Sphere & Polysaccharide & \begin{tabular}{|l|} 
Bone marrow \\
myeloid progenitor \\
cells from NOD mice \\
myeloid progenitor \\
cell
\end{tabular} & $\begin{array}{l}\text { The result demonstrate that } \\
\text { RME (receptor-mediated } \\
\text { endocytosis) of magnetic } \\
\text { nanoparticles effectively labels } \\
\text { DCs in vitro, the labeling } \\
\text { procedure does not harm the } \\
\text { cell's immunological function } \\
\text { and labeled cells can be } \\
\text { visualized in vivo in a } \\
\text { longitudinal fashion. }\end{array}$ \\
\hline
\end{tabular}

Table 1. Summary of selected cytotoxicity and bio-imaging for various nanoparticles, 2003-2012. 


\subsection{Biomedical applications of quantum dots}

Quantum dots with their extensive excitation spectra, sharp emission spectra, and easily tunable emission properties are hypothetical candidates for replacing conventional fluorescent markers in biodetection assays. Having already shown considerable promise as intracellular imaging and tracking agents [68] quantum dots made of CdSe and ZnS, with few exceptions [69] have not been widely investigated as materials for biodetection assays. The first example of chemically modifying CdSe quantum dots with DNA involved ligand exchange coupled with particle surface engineering [70]. Recent studies employed quantum dots as labels imbedded in polymeric structures [71].

\subsection{Electrical detection using nanowire and nanotubes}

Nanotubes and nanowires are being reconnoitered as new signal transduction motifs in the electrical detection of DNA as they have for the detection of gases [72], small molecules [73] and proteins. For example, Lieber and colleagues demonstrated that silicon nanowires functionalized with PNA can be used for real-time, label-free detection of DNA at concentrations as low as $10 \mathrm{fM}[74]$.

\subsection{Biomedical applications of carbon nanotubes}

CNTs have very interesting physicochemical properties, such as ordered structure with high aspect ratio, ultra-light weight, high mechanical strength, high electrical conductivity, high thermal conductivity, metallic or semi-metallic behaviour and high surface area. The combination of these characteristics makes CNTs unique materials with the potential for diverse applications $[75,76]$. Cui et al. examined the influence of single-walled carbon nanotubes (SWCNTs) on human HEK293 kidney cells with the aim to explore SWCNT biocompatibility [77].

\subsection{Biomedical application of silver nanoparticles}

Silver nanoparticles are being used increasingly in wound dressing, catheters and various household products due to their antimicrobial activity. AshaRani et al. [78] reported that silver nanoparticles are cytotoxic, genotoxic and antiproliferative. As a general rule, the DNA damaging agents have the potential to cause genome instability, which is predisposing factor carcinogenesis. Future applications of $\mathrm{Ag}$ nanoparticles as an antiproliferative agent could be limited by the fact that it is equally toxic to normal cells [78]. Nevertheless, Sanpui et al. [79] reported, induction of appotosis in cancer cells at low silver nanoparticles concentration using chitosan nanocarrier. They used chitosan coated silver nanoparticles for successful delivery of silver nanoparticles to human colon cancer cells, HT 29 adenocarcinoma cells and demonstrated that the concentration of Ag nanoparticles required to reduce the viability of HT 29 cells by $50 \%$ was $0.33 \mu \mathrm{g} \mathrm{mL}^{-1}$, much less than in previously reported data. These reports indicate that though silver nanoparticles are 
harmful to normal cells, their use at low concentration could be exploited for biomedical applications.

\subsection{Future prospects}

Lot of work on in-vitro diagnostics has been carried out and related to specific detection, imaging, and therapy for very particular target cells. Various size and shaped nanoparticles of different materials have specific applications; e.g. spherical gold nanoparticles can be used for drug delivery, however for site specific drug delivery we need to use viable mechanism such as antibody-antigene mechanism. Here, rod shaped nanoparticles could be the best option, due to its more infrared absorption property as compare to spherical gold nanoparticles. Gold nanorods would be better option for drug delivery and phototherapy. However, rod shaped magnetic nanoparticles such as iron oxide coated by gold shells can be better option for hyperthermia and phototherapy. Moreover, the combination of iron oxide@Au@drug composite would be best option for hyperthermia, site specific drug delivery and chemotherapy. Nowadays, researchers in cancer therapy are realizing that instead of single therapy, multi-therapy would be the best option. It has great future in cancer therapy, if drug would be loaded on the surface of iron oxide@Au nanoparticles and make it iron oxide@Au@drug nanomaterials. Rod shaped magnetic nanoparticles coated by gold nanoshell are an attractive alternative to traditional organic fluorescent dyes in that they do no photo bleach, they can absorb throughout the visible and NIR, and they can be nontoxic under certain experimental conditions. In the next 5-10 years, intensive research activity should be focused on in-vivo uses of rod shaped gold nanoparticles, rod shaped iron oxide@Au core-shell nanoparticles and drug loaded rod shaped iron oxide@Au core-shell nanomaterials. Most of the cytotoxicity studies are in progress for every size shape and type of nanomaterials along with surfactants in in-vitro and few of them in in-vivo. This should be continued along with study of their side effects.

The majority of commercial nanoparticles applications in medicine are geared towards drug delivery. There are some developments in directing and remotely controlling the functions of nano-probes, for example driving magnetic nanoparticles to the tumour and then making them either to release the drug load or just heating them in order to destroy the surrounding tissue [80]. However, multi-therapy in cancer treatment is advocated by many researchers, which also suggests that experts from various discipline should come together to kill cancer problem before it will be too late. These also suggest that there is no place for compartmentalized treatment to the knowledge in their own box rather tailoring together is and would be the only and lonely solution and need of the time.

\section{Conclusion}

Size, shape and surface coating of nanomaterials are critical parameter which effects cell uptake and/or the rate and site specific drug delivery from the system. Shapes of nanomaterials are also play important role in infrared absorption, which has special significance in phototherapy. Anisotropic nanoparticles such as rod and triangular shaped 
gold nanoparticles strongly absorb in visible and NIR region. This special property of gold anisotropic nanoparticles could be exploited in hyperthermia of tumors. For site specific drug delivery magnetic particles such iron oxide could be the best option under the influence of alternating magnetic field. However, mere iron oxide nanoparticles did not prove the best option for cancer therapy. Nevertheless, iron oxide nanoparticles coated by gold shell along with loaded anticancer drug would be the best option for hyperthermia, phototherapy and chemotherapy together. In conclusive remark, I could not resist mentioning, one should not forget that the main reason of any kind of diseases is our life style, which includes our food style, regular sufficient sleep/rest and foremost important key point is our thinking or will power.

\section{Author details}

Balaprasad Ankamwar

Bio-Inspired Materials Science Laboratory, Department of Chemistry, University of Pune, Ganeshkhind, Pune, India

\section{Acknowledgement}

The author grateful to Prof. Ru-Shi Liu, National Taiwan University and Prof. Michael Hsiao, Genomics Research Center, Academia Sinica, Taipei, Taiwan for biocompatibility studies of $\mathrm{Fe}_{3} \mathrm{O}_{4}$ nanoparticles evaluated by in-vitro cytotoxicity assays using normal, glia and breast cancer cells, supported by the grants from National Science Council of Taiwan (NSC 97-2113-M-002-012-MY3). The author also thanks his project students Ms. Farah Surti and Annsi Jose I. for help in refining schematic diagrams.

\section{References}

[1] Shiv Shankar S, Rai A, Ankamwar B, Singh A, Ahmad A, Sastry M (2004) Biological Synthesis of Triangular Gold Nanoprisms. Nat. Mate. 3: 482-488.

[2] Da Costa K, Dmitriev V(2010) Comparative Analysis of Circular and Triangular Gold Nanodisks for Field Enhancement Applications. J. Microw. Optoelectron. Electromagn. Appl. 2: 123-130.

[3] Ankamwar B, Chaudhary M, Sastry M (2005) Gold Nanotriangles Biologically Synthesized using Tamarind Leaf Extract and Potential Applications in Vapor Sensing. Syn. React. Inorg. Metal Org. Nano-Metal Chem. 35: 19-26.

[4] Ankamwar B, Lai T, Huang J, Liu R, Hsiao M, Chen C, Hwu Y (2010) Biocompatibility of $\mathrm{Fe}_{3} \mathrm{O}_{4}$ Nanoparticles Evaluated by in vitro Cytotoxicity Assays using Normal, Glia and Breast Cancer Cells. Nanotechnology 21: 075102 (9pp).

[5] Ankamwar B (2010) Biosynthesis of Gold Nanoparticles (Green-gold) using Leaf Extract of Terminalia catappa. E-J.Chem. 7 (4): 1334-1339.

[6] Kandil F, Soliman A, Skodack S, Mabry T (1999) A new Anticancer Tannin and Known Tannins from Terminalia catappa. Asian J. Chem. 11: 1001-1004. 
[7] Pawar S, Pal S (2002) Antimicrobial Activity of Extracts of Terminalia catappa Root. Indian J. Med. Sci. 56(6): 276-278.

[8] Lin C, Hsu Y, Lin T (2001) Modifying Effects of Terminalia catappa on AzoxymethaneInduced Colon Carcinogenesis in Male F344 Rats. Anticancer Res. 21: 237-243.

[9] Wang X, Liu L, Ramstro“ O, Yan M (2009) Engineering Nanomaterial Surfaces for Biomedical Applications Exp. Biol. Med. 234: 1128-1139.

[10] Pissuwani D, Valenzuela S, Cortie M (2008) Prospects for Gold Nanorod Particles in Diagnostic and Therapeutic Applications. Biotechnol. Genet. Eng. Rev. 25: 93-112.

[11] Chithrani B, Ghazani A, Chan W (2006) Determing the Size and Shape Dependence of Gold Nanoparticle Uptake into Mammalian Cells. Nano Lett. 6: 662-668.

[12] Osaki F, Kanamori T, Sando S Sera T, Aoyama Y (2004) J. Am. Chem. Soc. 126: 6250-1.

[13] Huang X, Jain P, El-Sayed I, El-Sayed M (2007) Special Focus: Nanoparticles for Cancer Diagnosis and Therapeutics - Review. Nanomedicine 2: 681-693.

[14] Granqvist C, Buhrman C, Wyns J, Sievers A (1976) Far-Infrared Absorption in Ultrafine Al Particles. Phys. Rev. Lett. 37: 625-629.

[15] Guidelines for Nanotoxicology Researchers using Nanocomposix Materials February 2012, v 1.0, Nanocomposix.com

[16] Chandra M, Indi S, Das P (2007) J. Phys. Chem. C. 111: 1065.

[17] Segets D, Tomalino L, Gradl J, Peukert W (2009) J. Phys. Chem. C. 113: 11995.

[18] Boyd R. Nonlinear Optics. San Diego, CA: Academic Press; 1992.

[19] Griffin J, Singh A, Senapati D, Rhodes P, Mitchell K, Robinson B, Yu E, Ray P (2009) Size- and Distance-Dependent Nanoparticle Surface-Energy Transfer (NSET) Method for Selective Sensing of Hepatitis C Virus RNA. Chem. Eur. J. 15: 342.

[20] Liu J, Cao Z, Lu Y (2009) Functional Nucleic Acid Sensors. Chem. Rev. 109: 1948.

[21] Li D, Song S, Fan C (2010) Target-responsive Structures for Nucleic Acid Sensors. Acc. Chem. Res. 43: 631-641.

[22] Zhang H, Banfield J (2009) Identification and Growth Mechanism of ZnS Nanoparticles with Mixed Cubic and Hexagonal Stacking J. Phys. Chem. C. 113: 9681-9687.

[23] Rodriguez E, Cid B, Antonio M, Ivanenko V, Lipovskii A (2009) Chem. Phys. Lett. 467: 335.

[24] Duboisset I, Russier-Antoine E, Benichou G, Jonin B, Brevet P. (2009) Single Metallic Nanoparticle Sensitivity with Hyper Rayleigh Scattering. J. Phys. Chem. C. 113: 13477.

[25] Singh A, Senapati D, Wang S, Griffin J, Neely A, Candice P, Naylor K, Varisli B, Kalluri J, Ray P (2009) Gold Nanorod Based Selective Identification of Escherichia coli Bacteria Using Two-Photon Rayleigh Scattering Spectroscopy. ACS Nano. 3: 1906.

[26] Ray P (2010) Size and Shape Dependent Second Order Nonlinear Optical Properties of Nanomaterials and Its Application in Biological and Chemical Sensing. Chem. Rev. 110: 5332-5365.

[27] Muller R, Keck C (2004) Challenges and Solutions for the Delivery of Biotech Drugs - A Review of Drug Nanocrystal Technology and Lipid Nanoparticles. J. Biotech. 113: 151170.

[28] Moghimi S, Hunter A, Murray J (2001) Long-circulating and Target-specific Nanoparticles: Theory to Practice. Pharmacol. Rev. 53: 283-318. 
[29] Lia X (2012) J. Appl. Phys. 111: 024702.

[30] Pan Y, Neuss S, Leifert A, Fischler M, Wen F, Simon U, Schmid G, Brandau W, JahnenDechent W (2007) Size-Dependent Cytotoxicity of Gold Nanoparticles. Small 3: 1941 1949.

[31] Sun S, Zeng H, Robinson D, Raoux S, Rice P, Wang S, Li G (2004) J. Am. Chem. Soc.126: 273-9.

[32] Wisse E, Braet F, Luo D, De Zanger R, Jans D, Crabbé E, Vermoesen A (1999) Structure and Function of Sinusoidal Lining Cells in the Liver. Toxicol. Pathol. 24: 100-11.

[33] Yuan F, Dellian M, Fukumura D, Leunig M, Berk D, Torchilin V, Jain R (1995) Vascular Permeability in a Human Tumor Xenograft: Molecular Size Dependence and Cutoff Size. Cancer Res. 55: 3752-6.

[34] Elsabahy M, Wooley K (2012) Chem. Soc. Rev. 41: 2545-2561.

[35] Vacha R, Martinez-Veracoechea F, Frenkel D (2011) Nano Lett. 11: 5391-5395.

[36] Reynwar B, Illya G, Harmandaris V, Muller M, Kremer K, Deserno M (2007) Nature 447: 461-4.

[37] Yang K, Ma Y (2010) Nat. Nanotechnol. 5: 579-583.

[38] Harris J, Martin N, Modi M. (2001) A Novel Process for Modifying Pharmacokinetics. Clin. Pharmacokinet. 40: 539-51.

[39] Adams M, Lavasanifar A, Kwon G (2003) Amphiphilic Block Copolymers for Drug Delivery. J. Pharm. Sci. 92: 1343-55.

[40] Chien, W, Szkopek T (2008)) Multiple- Multipole Simulation of Optical Near Fields in Discrete Metal Nanospheres Assemblies. OpEx. 16: 1820 - 1835.

[41] http://www.understandingnano.com/nanomedicine-nanorod-targeted-drugdelivery.html

[42] van der Zee J. (2002) Annals of Oncology 13: 1173-1184.

[43] Wust P, Hildebrandt B, Sreenivasa G et al. (2002) Lancet Oncology. 3(8): 487-497.

[44] Berry C, Curtis A (2003) Funtionalisation of Magnetic Nanoparticles for Applications in Biomedicine. J. Phys. D: Appl. Phys. 36: R198-R206.

[45] Jordan A Wust P, Scholz R, Tesche B, Fahling H, Mitrovics T, Vogl T, Cervos-Navarro J, Felix R (1996) Cellular Uptake of Magnetic Fluid Particles and theirEffects on Human Adenocarcinoma Cells Exposed to AC Magnetic Fields in-vitro. Int. J. Hyperthermia 12: 705-22.

[46] Neilsen O, Horsman M, Overgaard J (2001) E. J. Cancer. 37: 1587-1589.

[47] Mitsumori M, Hiraoki M, Shibata T, Okuno Y, Nagata Y, Nishimura Y, Abe M, Hasegawa M, Nagae H, Ebisawa Y (1996) Targeted Hyperthermia Using Dextran Magnetite Complwe: A New Treatment Modality for Liver Tumors. HepatoGastroenterology 43: 1431-1437.

[48] Rehman J, Landman J, Tucker R, Bostwick D, Sundaram C, Clayman R (2002) Ferromagnetic Self-Regulating Reheatable Thermal Rd Implants for in-situ Tssue Ablation. J. Endourol. 16: 523-531.

[49] Hilger I, Fruhauf K, Andra W, Hiergeist R, Hergt R and Kaiser W A (2002) Acad. Radiol. 9: 198-202. 
[50] Hilger I, Andra W, Hergt R, Hiergeist R, Schubert H, Kaiser W A (2001) Electromagnetic Heating of Breast Tumours in Interventional Radiology: in-vitro and in-vivo Studies in Human Cadavers and Mice. Radiology 218: 570-575.

[51] Babinkova M, Leszczynska D, Sourivong P, Babinec P (2000) Med. Hypoth. 54: 177-179.

[52] Babinkova M Sourivong P, Leszczynska D, Babinec P (2000) Blood-Specific Whole-Body Electromagnetic Hyperthermia. Med. Hypoth. 55: 459-460.

[53] Gupta A, Berry C, Gupta M, Curtis A (2003) Receptor -Mediated Targeting of Magnetic Nanoparticles Using Insulin as a Surface Ligand to Prevent Endocytosis. IEEE Transactions on NanoBioscience 2: 255-261.

[54] http://www.ibridgenetwork.org/utah/targeted-combination-drug-delivery-andphotothermal-therapy-f_1

[55] Hirsch L, Gobin A, Lowery A, Tam F, Drezek R, Halas N, West J (2006) Ann. Biomed. Eng. 34: 15-22.

[56] Pan J, Fen S (2009) Targeting and Imaging Cancer Cells by Folate-Decorated Quantum Dots (QDs)- Loaded Nanoparticles of Biodegradable Polymers. Biomaterials 30: 11761183.

[57] Niidome T, Yamagata M, Okamoto Y, Akiyama Y, Takahashi H, Kawano T, Katayama Y, Niidome Y (2006) PEG-Modified Gold Nanorods with a Stealth Character for in vivo Applications. J. Control. Release. 114: 343-347.

[58] Takahashi H, Niidome Y, Niidome T, Kaneko K, Kawasaki H, Yamada S (2006) Modification of Gold Nanorods Using Phosphatidylcholine to Reduce Cytotoxicity. Langmuir 22: 2-5.

[59] Liang S, Chen H , Zhang Z, Yang Q , Tong H , Xu A, Wang C (2012) J. Inorg. Biochem. 108: 47-52.

[60] Temminka O, Hoebea E, Fukushim M, Peters G (2007) Irinotecan-Induced Cytotoxicity to Colon Cancer Cells in-vitro is Stimulated by Pre-Incubation with Trifluorothymidine. E. J. Cancer 43: 175-183.

[61] Wei G, Yan M, Ma L, Zhang H (2012) The Synthesis of Highly Water-Dispersible and Targeted CdS Quantum Dots and it is used for Bioimaging by Confocal Microscopy. Spectrochim. Acta Part A 85: 288-292.

[62] Abbasalipourkabir R, Abdullah A (2011) Cytotoxicity Effect of Solid Lipid Nanoparticles on Human Breast Cancer Cell Lines. Biotech. 10: 528-533.

[63] Pourgholami M, Wangoo K, Morris D (2008) Albendazole-Cyclodextrin Complex: Enhanced Cytotoxicity in Ovarian Cancer Cells. Anticancer Research 28: 2775-2780.

[64] Yong K, Indrajit Roy I, Swihart M,Prasad P(2009) Multifunctional Nanoparticles as Biocompatible Targeted Probes for Human Cancer Diagnosis and Therapy. J. Mater. Chem. 19: 4655-4672.

[65] Glazer E, Steven A. Curley S, (2010) Radiofrequency Field-Induced Thermal Cytotoxicity in Cancer Cells Treated with Fluorescent Nanoparicles. Cancer 116: 32853293.

[66] Das M, Mishra D, Maiti T, Basak A, Pramanik P (2008) Bio-Functionalization of Magnetite Nanoparticles Using an Aminophosphonic Acid Coupling Agent: New, 
Ultradispersed, Iron-Oxide FlateNanoconjugates for Cancer-Specific Targeting. Nanotechnology 19: 415101 (14pp).

[67] Ahrens E, Feili-Hariri M, Xu H, Genoye G, Morel P (2003) Mag. Reso. Med. 49: 1006-13.

[68] Gao X, Cui Y, Levenson R, Chung L, Nie, S. (2004) In-vivo Cancer Targeting and Imaging with Semiconductor Quantum Dots. Nat. Biotechnol. 22: 969.

[69] Gerion D, Chen F, Kannan B, Fu A Parak W, Chen D, Majumdar A, Alivisatos A (2003) Anal. Chem. 75: 4766

[70] Mitchell, G. P.; Mirkin, C. A.; Letsinger, R. L. (1999) J. Am. Chem. Soc. 121: 8122.

[71] Han M, Gao X, Su J, Nie S (2001) Nat. Biotechnol. 19: 631.

[72] Patolsky F, Zheng G, Hayden O, Lakadamyali M, Zhuang X, Lieber C (2004) Electrical Detection of Single Viruses. Proc. Natl. Acad. Sci. 101: 14017.

[73] Wang J, Musameh M (2003) Enzyme-Dispersed Carbon-Nanotube Electrodes: A Needle Microsensor for Monitoring Glucose. Analyst 128: 1382.

[74] Hahm J, Lieber C (2004) Direct Ultrasensitive Electrical Detection of DNA and DNA Sequence Variations Using Nanowire Nanosensors. Nano Lett. 4: 51.

[75] Klumpp C, Kostarelos K, Prato M, Bianco A (2006) Functionalized Carbon Nanotubes as Emerging Nanovectors for the Delivery of Therapeutics. Biochim. Biophys. ActaBiomembr. 1758: 404-12.

[76] Kostarelos $\mathrm{K}$ et al (2007) Cellular Uptake of Functionalized Carbon nanotubes is Independent of functional Group and Cell Type. Nat. Nanotechnol. 2: 108-113.

[77] Cui D, Tian F, Ozkan C, Wang M, Gao H (2005) Effect ofSingle Wall Carbon Nanotubes on Human HEK293 Cells. Toxicol. Lett. 155: 73-85.

[78] AshaRani A, Mun G, Hande M, Valiyaveettil S (2009) Cytotoxicity and Genotoxicity of Silver Nanoparticles in Human Cells. ACS Nano. 2: 279-290.

[79] Sanpui P, Chattopadhyay A, Ghosh S (2011) Induction of Apoptosis in Cancer Cells at Low Silver Nanoparticle Concentrations using Chitosan Nanocarrier ACS Appl. Mater Interfaces. 3: 218-228.

[80] Salata O (2004) Applications of Nanoparticles in Biology and Medicine. J. Nanobiotech. 2: $1-6$. 